\title{
Effect of graft choice on the outcome of revision anterior cruciate ligament reconstruction in the Multicenter ACL Revision Study (MARS) Cohort
}

\author{
A full list of authors and affiliations appears at the end of the article.
}

\begin{abstract}
Background-Most surgeons believe that graft choice for ACL reconstruction is an important factor related to outcome. Although graft choice may be limited in the revision setting based on previously used grafts, it is still felt to be important.

Hypothesis-The purpose of this study was to determine if revision ACL graft choice predicts outcomes related to sports function, activity level, OA symptoms, graft re-rupture, and reoperation at two years following revision reconstruction. We hypothesized that autograft use would result in increased sports function, increased activity level, and decreased OA symptoms (as measured by validated patient reported outcome instruments). Additionally, we hypothesized that autograft use would result in decreased graft failure and reoperation rate 2 years following revision ACL reconstruction.
\end{abstract}

Study Design-Prospective cohort study; Level of evidence, 2.

Methods-Revision ACL reconstruction patients were identified and prospectively enrolled by 83 surgeons over 52 sites. Data collected included baseline demographics, surgical technique and pathology, and a series of validated patient reported outcome instruments (IKDC, KOOS, WOMAC, and Marx activity rating score). Patients were followed up at 2 years, and asked to complete the identical set of outcome instruments. Incidence of additional surgery and reoperation due to graft failure were also recorded. Multivariate regression models were used to determine the predictors (risk factors) of IKDC, KOOS, WOMAC, Marx scores, graft re-rupture, and reoperation rate at 2 years following revision surgery.

Results-1205 patients were successfully enrolled with 697 (58\%) males. Median age was 26. In $88 \%$ this was their first revision. 341 (28\%) were undergoing revision by the surgeon that had performed the previous reconstruction. $583(48 \%)$ underwent revision reconstruction utilizing an autograft, 590 (49\%) allograft, and $32(3 \%)$ both autograft and allograft. Median time since their last ACL reconstruction was 3.4 years. Questionnaire follow-up was obtained on 989 subjects (82\%), while phone follow-up was obtained on 1112 subjects (92\%). The IKDC, KOOS, and WOMAC scores (with the exception of the WOMAC stiffness subscale) all significantly improved at the two year follow-up time point $(\mathrm{p}<0.001)$. In contrast, the two year MARX activity scale demonstrated a significant decrease from the initial score at enrollment $(\mathrm{p}<0.001)$.

Corresponding Author: Rick W. Wright, MD, Washington University St. Louis, 660 S. Euclid Ave, Campus Box 8233, St. Louis, MO 63110, Phone: 314-747-2639, rwwright1@aol.com. 
Graft choice proved to be a significant predictor of 2 year IKDC scores ( $\mathrm{p}=0.017$ ). Specifically, the use of an autograft for revision reconstruction predicted improved score on the IKDC $[\mathrm{p}=0.045$; Odds Ratio $(\mathrm{OR})=1.31 ; 95 \%$ confidence intervals $(\mathrm{CI})=1.01,1.70]$. The use of an autograft predicted an improved on the KOOS subscale Sports and Recreation ( $\mathrm{p}=0.037$; $\mathrm{OR}=1.33 ; 95 \% \mathrm{CI}=1.02,1.73)$. Use of an autograft also predicted improved scores on the KOOS subscale Quality of Life (QOL) ( $\mathrm{p}=0.031 ; \mathrm{OR}=1.33 ; 95 \% \mathrm{CI}=1.03,1.73$ ). For the KOOS Symptoms and ADL subscales, graft choice did not predict outcome score. Graft choice also proved to be a significant predictor of 2 year Marx activity level scores $(\mathrm{p}=0.012)$.

Graft re-rupture was reported in 37/1112 (3.3\%) of patients by their two year follow-up: 24 allografts, 12 autografts, and 1 allograft + autograft. Use of an autograft for revision resulted in patients 2.78 times less likely to sustain a subsequent graft rupture than if an allograft was utilized ( $\mathrm{p}=0.047 ; 95 \% \mathrm{CI}=1.01,7.69)$.

Conclusions-Improved sports function and patient reported outcome measures are obtained when an autograft is utilized. Additionally, use of an autograft shows a decreased risk in graft rerupture at two years follow-up. No differences were noted in rerupture or patient reported outcomes between soft tissue and bone-patellar tendon-bone grafts. Surgeon education regarding the findings in this study can result in potentially improved revision ACL reconstruction results for our patients.

\section{Key Terms}

Anterior Cruciate Ligament; ACL Revision; Graft; Outcomes

\section{Introduction}

Revision anterior cruciate ligament (ACL) reconstruction remains challenging for patients and surgeons. Multiple studies have demonstrated worse clinical outcomes for revision reconstructions as compared to primary reconstructions. ${ }^{5,13,25,26}$ These outcomes combined with confirmatory beliefs by orthopedic sports medicine surgeons resulted in the development of the MARS group. The goal was to establish a prospective longitudinal cohort to evaluate the predictors of outcome in ACL revision reconstruction.

Most surgeons believe that graft choice for ACL reconstruction is an important factor related to outcome. Less outcome evidence exists in the revision setting compared to primary ACL reconstruction, but most surgeons believe it remains important. Graft choice may be limited in the revision setting based on previously used grafts. Thus, surgeons are interested in the impact of both allograft versus autograft and soft tissue versus patellar tendon choices to determine how important it is to pursue different grafts in the revision setting. Previous prospective cohorts have demonstrated an increased failure rate of allografts in young, high activity patients. ${ }^{12}$ As such, one of the goals of our prospective MARS cohort was to determine if this remained true in the revision setting or if more modern allograft processing and other factors in the revision setting would result in a similar allograft/autograft failure rate. 
The purpose of this study was to determine if graft choice predicts outcomes related to sports function, activity level, osteoarthritis (OA) symptoms, graft re-rupture, and reoperation at two years following revision $\mathrm{ACL}$ reconstruction. We hypothesized that autograft use would result in increased sports function, increased activity level, and decreased OA symptoms (as measured by validated patient reported outcome instruments). Additionally, we hypothesized that autograft use would result in decreased graft failure and reoperation rate2 years following revision ACL reconstruction.

\section{Methods}

\section{Setting and Study Population}

The MARS group is comprised of 83 surgeons over 52 sites. Surgeons were a 50/50 mix of academic and private practitioners that were all sports medicine fellowship trained. Enrollment began in 2006 and ended June 30, 2011, in which 1205 revision ACL reconstruction patients were enrolled in this prospective longitudinal cohort.(Figure 1) Inclusion criteria incorporated any patients undergoing revision of a previously failed ACL reconstruction who agreed to participate and filled out an informed consent and a series of patient reported outcome instruments. Multi-ligament reconstructions were excluded. Surgeon inclusion criteria was comprised of completion of a training session that integrated articular cartilage and meniscus agreement studies, review of study design and patient inclusion criteria and a review of the surgeon questionnaire. Surgeons performed the surgery as they desired with the only stipulation that if an allograft was used it must be supplied by the Musculoskeletal Transplant Foundation (MTF; Edison, NJ). This was a stipulation to control and make consistent allograft source and processing given the importance of the allograft versus autograft question. Processing of the allografts was as follows: MTF used a technique for evaluating the incoming tissue called The Vanguard Method ${ }^{\mathrm{TM}}$. MTF took actual samples of bone and soft tissue from every area that was to be used for transplantable grafts and destructively tested them which told potential organism and bioburden. From these results the tissue had 4 potential pathways: 1 ) solely processed aseptically; 2) depending on the type of organism and level, the tissue was discarded entirely; 3) the whole donor was sent for a bulk tissue gamma radiation treatment of 1.2-1.8 mRAD as a pretreatment step prior to processing; or 4) in a small number of cases due to surgeon request terminal irradiation of 0.7-1.0 mRAD was delivered. Of the patients that received allografts 247 (42\%) were processed aseptically, 313 (53\%) received low dose whole body irradiation and $31(5 \%)$ received $0.7-1.0 \mathrm{mRAD}$ terminal irradiation.

\section{Data Sources and Measurement}

After informed consent was obtained, each participant completed a 13-page questionnaire that encompassed baseline demographics, injury descriptors, sports participation level, comorbidities, knee surgical history, and patient reported outcome measures that included the International Knee Documentation Committee (IKDC),${ }^{10}$ Knee injury and Osteoarthritis Outcome Score (KOOS) five subscales (symptoms, pain, activities of daily living [ADL], sports and recreation, knee-related quality of life), ${ }^{18-20}$, the Western Ontario and McMaster Universities Osteoarthritis Index (WOMAC), ${ }^{1,2,8}$ and the Marx activity rating scale. ${ }^{15}$ Their validity, reliability, responsiveness to clinical change, and minimal clinically meaningful 
differences have been previously documented. ${ }^{23,24}$ All questionnaires were completed prior to the procedure.

Immediately following the surgical procedure, each surgeon completed a 49-page questionnaire that documented the results of the exam under anesthesia, surgical technique, and the arthroscopic findings and treatment of concomitant meniscal and cartilage injury. ${ }^{7}$ Surgeon documentation of articular cartilage injury was recorded based on the modified Outerbridge classification. ${ }^{16}$ Meniscus injuries were classified by size, location, and partial versus complete tears, while treatment was recorded as not treated, repair, or extent of resection.

Completed data forms were mailed from each participating site to the data coordinating center. Data from both the patient and surgeon questionnaires were scanned with Teleform ${ }^{\mathrm{TM}}$ software (Cardiff Software, Inc., Vista, CA) utilizing optical character recognition, and the scanned data was verified and exported to a master database. A series of logical error and quality control checks were subsequently performed prior to data analysis.

\section{Patient Follow-up}

Two year follow-up was completed by mail with re-administration of the same questionnaire to each patient, which included the same outcome measures (IKDC, KOOS, WOMAC, MARX activity scale) as completed at baseline. Patients were also contacted by telephone to determine if graft failure and any subsequent surgeries had occurred since their initial revision reconstruction.

\section{Quantitative Variables and Statistical Methods}

Multivariable regression models were utilized to examine the independent (risk factor) variables and incidence of graft failure, reoperation rate, and sports function at two years following ACL revision surgery. For the ordinal outcome measures, analysis was performed using a proportional odds logistic regression model. Binary outcome measures analysis was performed using a logistic regression model. Parameter estimates were exponentiated to obtain odds ratios along with their corresponding 95\% confidence intervals. The dependent variables were treated as either categorical or continuous and consisted of graft failure (yes/ no), reoperation (yes/no), IKDC (scored 0 [worst] to 100 [best]), KOOS (scored 0 [worst] to 100 [best]), WOMAC (scored 0 [worst] to 100 [best]), and the Marx (scored 0 [low activity] to 16 [highest activity]). Independent patient-related covariates controlled for in the model included age at the time of surgery, gender, body mass index (BMI), smoking status, education level, activity level as assessed using the Marx activity rating scale, and baseline measure of the outcome (IKDC, KOOS, WOMAC, and Marx) (Table 1). All continuous covariates were modeled using a 3 knot restricted cubic spline to allow for a nonlinear relationship with the outcomes measures.

Independent surgical-related covariates controlled for in the model encompassed previous surgical characteristics and findings, as well as surgical characteristics and findings at the time of revision (Table 1). Previous surgical characteristics included the revision number, previous ACL reconstruction on the contralateral knee (yes/no), previous meniscal pathology, surgeon's opinion of cause of failure, and prior graft type. Time from previous 
ACL reconstruction (calculated as the time from the patient's previous ACL surgery to the date that the patient had their revision ACL surgery) was included in the model, and treated as a continuous variable. Current surgical characteristics included individual surgeon, mechanism of injury, current revision graft type (autograft, allograft, both), graft source (BTB, soft tissue, other), surgical technique, meniscal and articular cartilage pathology and treatment.

Regarding minimal clinically important difference (MCID) change in score, we utilized 11 points for the IKDC, ${ }^{11} 8$-10 points for the KOOS' five subscales, ${ }^{17}$ 8-10 points for the WOMAC $^{23,24}$ and 2 points for the Marx activity scale. To avoid casewise deletion of records with missing covariates we employed multiple imputation via prediction mean matching. Statistical analysis was performed with the free open source R statistical software using the Hmisc and rms package (http://www.r-project.org). ${ }^{9}$

\section{Results}

\section{Study Population}

Table 2 provides a synopsis of the baseline patient and surgical characteristics of our cohort. 1205 patients enrolled with 697 (58\%) males. Median age was 26. In 88\% this was their first revision. $341(28 \%)$ were undergoing revision by the surgeon that had performed the previous reconstruction. $50 \%$ of the surgeons were in private practice while $50 \%$ were involved in an academic practice. $583(48 \%)$ underwent revision reconstruction utilizing an autograft, 590 (49\%) allograft, and $32(3 \%)$ both autograft and allograft. Median time since their last ACL reconstruction was 3.4 years. A two stage procedure for bone grafting of tunnels was performed $7 \%$ of the time for the femur and $8 \%$ for the tibia.

\section{Two Year Follow-up}

Questionnaire follow-up was obtained on 989 subjects (82\%), while phone follow-up was obtained on 1112 subjects (92\%). There were 6 subjects who underwent a total knee arthroplasty by the 2 year follow-up, and as such, no follow-up questionnaire was required to be completed from these subjects.

\section{Patient Reported Outcomes (IKDC, KOOS, WOMAC, and Marx Activity Level)}

Table 3 summarizes and compares the median patient reported outcome scores between baseline and 2 years. The IKDC, KOOS, and WOMAC scores (with the exception of the WOMAC stiffness subscale) all significantly improved at the two year follow-up time point $(\mathrm{p}<0.001)$. These improvements all surpassed their respective MCIDs, illustrating that revision ACL surgery was beneficial to this cohort. However, the two year KOOS kneerelated quality of life subscale, although showing significant improvement at the 2 year mark (31 vs. 56), falls well below the previously reported primary ACL score of 75 at the same 2 year follow-up time. ${ }^{21}$

In contrast to the IKDC, KOOS, and WOMAC scores, the two year MARX activity scale demonstrated a significant decrease from the initial score at enrollment $(\mathrm{p}<0.001)$. At baseline the median score was an 11 (out of a 16 point scale) with the $75^{\text {th }}$ percentile score a 
16. At 2 years the median dropped to 7 and the $75^{\text {th }}$ dropped to 12 . To illustrate this point, we calculated the number of patients who scored either a " 0 " (lowest) or "16" (highest Marx value) at baseline, and compared it to the number of patients who rated themselves either "0" or "16" at two years. Only patients in which we had both baseline and 2 year Marx scores were included ( $\mathrm{n}=980)$. There were 124 patients who rated themselves a " 0 " at baseline (or $12.7 \%$ of our cohort), increasing to 165 patients at two years (16.8\% of our cohort; a $4 \%$ increase). Similarly, there were 281 patients who rated themselves a " 16 " at baseline (28.7\% of our cohort), which decreased to 109 subjects at two years (11.1\% of our cohort; a nearly $18 \%$ decrease). This reflects a substantial number of subjects who ratcheted down their frequency of playing high level sports (172 subjects), or essentially dropped their activity to sedentary levels (41 subjects).

\section{Influence of Graft Choice on Two Year Patient Reported Outcomes}

IKDC—Graft choice proved to be a significant predictor of 2 year IKDC scores $(\mathrm{p}=0.017)$. Specifically, the use of an autograft for revision reconstruction predicted improved score on the IKDC $[\mathrm{p}=0.045$; Odds Ratio $(\mathrm{OR})=1.31 ; 95 \%$ confidence intervals $(\mathrm{CI})=1.01,1.70]$. Subjects who had a combination autograft plus allograft (at the time of revision surgery, 32 patients) also had improved IKDC outcomes at 2 years ( $\mathrm{p}=0.022 ; \mathrm{OR}=2.77 ; 95 \% \mathrm{CI}=1.16$, 6.64). Additional factors that predicted an improved IKDC score included a higher baseline IKDC score $(\mathrm{p}<0.001 ; \mathrm{OR}=3.06 ; 95 \% \mathrm{CI}=2.50,3.74)$, male gender $(\mathrm{p}<0.001 ; \mathrm{OR}=1.64$; $95 \% \mathrm{CI}=1.25,2.13)$, a longer time since the last $\mathrm{ACL}$ reconstruction $(\mathrm{p}=0.010 ; \mathrm{OR}=1.92$; $95 \% \mathrm{CI}=1.30,2.82)$ and a higher baseline Marx activity score ( $\mathrm{p}=0.023 ; \mathrm{OR}=2.21 ; 95 \%$ $\mathrm{CI}=1.55,3.15)$.

KOOS-Knee sports and recreation score on the KOOS demonstrated higher scores in the setting of an autograft compared to allograft for revision reconstruction $(\mathrm{p}=0.037 ; \mathrm{OR}=1.33$; $95 \% \mathrm{CI}=1.02,1.73)$. Other factors which predicted improved score were similar to the IKDC, including a higher baseline KOOS sports/rec score ( $\mathrm{p}<0.001 ; \mathrm{OR}=2.97 ; 95 \%$ $\mathrm{CI}=2.42$, 3.63), higher baseline Marx score ( $\mathrm{p}=0.001 ; \mathrm{OR}=1.81 ; 95 \% \mathrm{CI}=1.26,2.59)$, and a longer time since previous reconstruction ( $\mathrm{p}=0.008 ; \mathrm{OR}=2.03 ; 95 \% \mathrm{CI}=1.38,2.99)$. For KOOS subscale quality of life (QOL) autograft also predicted improved scores ( $\mathrm{p}=0.031$; $\mathrm{OR}=1.33 ; 95 \% \mathrm{CI}=1.03,1.73$ ). For the KOOS symptoms and ADL subscales, graft choice did not predict outcome score.

WOMAC-The stiffness subscale on the WOMAC demonstrated higher scores in subjects who had a graft consisting of the combination of bone-tendon-bone (BTB) with a soft tissue graft $(n=14 ; \mathrm{p}=0.029 ; \mathrm{OR}=6.48 ; 95 \% \mathrm{CI}=1.22,34.57)$. Additional factors which predicted less knee stiffness via the WOMAC were better baseline WOMAC stiffness scores $(\mathrm{p}<0.001 ; \mathrm{OR}=4.34 ; 95 \% \mathrm{CI}=3.39,5.56)$ and a longer time since previous reconstruction $(\mathrm{p}=0.003 ; \mathrm{OR}=1.77 ; 95 \% \mathrm{CI}=1.19,2.63)$.

MARX - Graft choice also proved to be a significant predictor of 2 year Marx activity level scores ( $\mathrm{p}=0.012$ ). Specifically, the use of a combination autograft plus allograft for revision reconstruction predicted improved scores on the Marx ( $\mathrm{p}=0.005 ; \mathrm{OR}=3.33 ; 95 \% \mathrm{CI}=1.43$, 7.78). Additional factors which predicted an improved 2 year Marx activity level score 
included a higher baseline Marx score ( $\mathrm{p}<0.001 ; \mathrm{OR}=5.79 ; 95 \% \mathrm{CI}=4.01,8.35)$, male gender $(\mathrm{p}<0.001 ; \mathrm{OR}=1.79 ; 95 \% \mathrm{CI}=1.39,2.33)$, younger age $(\mathrm{p}<0.001 ; \mathrm{OR}=2.17 ; 95 \%$ $\mathrm{CI}=1.41,3.23)$, and if it was the surgeon's own failure $(\mathrm{p}=0.017 ; \mathrm{OR}=1.54 ; 95 \% \mathrm{CI}=1.08$, 2.19). Factors which predicted a lower activity level at 2 years included subjects who were current smokers at the time of revision surgery $(\mathrm{p}=0.018 ; \mathrm{OR}=1.72 ; 95 \% \mathrm{CI}=1.10,2.70)$, subjects having a previous ACL reconstruction on the contralateral leg ( $\mathrm{p}=0.047 ; \mathrm{OR}=1.49$; $95 \% \mathrm{CI}=1.01,2.22)$, and those incurring a biologic enhancement at the time of revision surgery $(\mathrm{p}=0.019 ; \mathrm{OR}=1.82 ; 95 \% \mathrm{CI}=1.11,3.03)$.

\section{Influence of Graft Choice on Predicting Graft Re-rupture and Reoperations at Two Years Graft Re-rupture}

Graft re-rupture was reported in 37/1112 (3.3\%) of patients by their two year follow-up: $24 / 540$ (4.4\%) allografts, $12 / 542$ (2.2\%) autografts, and 1/29 (3.4\%) allograft + autograft. Subjects with an autograft revision were found to have a 2.78 times less likely risk of sustaining a subsequent graft rupture than if an allograft was utilized ( $\mathrm{p}=0.047 ; 95 \%$ $\mathrm{CI}=1.01,7.69)$. The 25 patients that had rerupture with an allograft included $13(52 \%)$ treated aseptically, $11(44 \%)$ treated with whole body irradiation and $1(3 \%)$ treated with terminal irradiation. The use of BTB versus soft tissue grafts did not impact graft re-rupture rate for either allograft or autograft usage. Analysis of additional predictors for graft re-rupture demonstrated that the number of previous revisions significantly predicted risk for future graft rupture. Specifically, patients undergoing revision number 3 or higher were 25.8 times more likely to sustain a subsequent graft re-rupture by 2 years following their enrollment surgery $(\mathrm{p}=0.021 ; \mathrm{CI}=1.65,400)$.

\section{Reoperation}

One hundred fifty $(150 / 1112$, or $13.5 \%)$ patients underwent reoperation in the 2 years since their revision reconstruction. For this specific analysis, we eliminated reoperations that included meniscal transplant $(n=4)$, high tibial osteotomy $(n=6)$ and knee replacement $(n=6)$ because we believe that these were not related to graft choice. The included reoperations in the analysis were chondroplasty and other articular cartilage treatment procedures, meniscectomy, meniscal repair and hardware removal. Analysis demonstrated that graft choice was not a predictor of incidence of subsequent reoperations at two years following revision surgery. However, patients undergoing their $3^{\text {rd }}$ revision or higher were 4.7 times

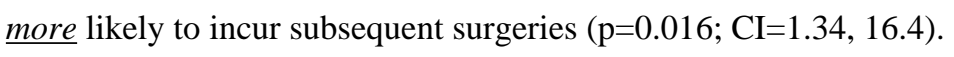

\section{Discussion}

This study demonstrates the successful ability of the MARS group to prospectively collect and analyze a large revision ACL reconstruction cohort and has many strengths. To our knowledge, this is the largest revision ACL reconstruction patient cohort ever studied. Previously, in the 21 studies with minimum 2 year follow-up analyzed by systematic review there was a collective total of 863 patients in the entire 21 studies. ${ }^{26}$ This current cohort with follow-up on greater than 1000 patients eclipses the collective previous patients documented in the medical literature. The large cohort $(n=1205)$ allows for inclusion of a large number of variables (88) to be controlled for in the modeling, while keeping within statistical rules 
requiring 10 subjects per variable for multivariate analysis. Based on the 50/50 mix of the academic and private practice surgeons our results are generalizable to the sports medicine community. Our findings support our hypothesis that graft choice was a predictor for 2 year revision ACL reconstruction outcomes. Specifically, the use of autograft resulted in improved sports function and activity level as measured by patient reported outcome measures. Also consistent with our hypothesis was that the use of autograft decreased the likelihood of subsequent graft rupture.

The findings that autograft use predicted higher sports function and activity level and decreased graft rerupture at two years will require continued surveillance. In our study, those who had an autograft were 2.78 times less likely to incur an additional revision ACL reconstruction compared with patients with an allograft. But given the few number of events in this category, the power to detect a difference is low. As such, these findings should be approached with caution. Additionally, the impact of bone-tendon-bone versus soft tissue grafts while not a predictor for the current study will require additional study with longer follow-up.

Reoperation following revision ACL reconstruction is not an uncommon occurrence. Our rate of $13.5 \%$ reflects this. This has not been a common focus in previous studies. ${ }^{26}$ It does reflect an occurrence that should be discussed with patients preoperatively since one in eight may require further surgery following revision. Analyzing the predictors for reoperation does not lend itself to issues that are modifiable from a surgeon's standpoint and thus will remain a future issue despite our study.

The debate regarding the indications and outcomes of allograft versus autograft ACL reconstruction has existed for several years. Graft choice remains a topic of high interest for surgeons performing primary and revision ACL reconstructions. $3,4,14$ The key factors appear to be mode of processing of the allograft and the age and activity of the patient receiving the graft. ${ }^{3,12} \mathrm{We}$ chose to standardize the source and processing of the allografts in this cohort. The MTF grafts were all fresh frozen with minimal ( $\leq 1.8$ mRAD) to no irradiation. This is thought to represent the best case scenario for allografts. Different processing approaches by other allograft sources may be better, but the evidence regarding this is unavailable. An additional factor for revision reconstruction graft choice is when previously an autograft was utilized and thus that specific graft is lost for consideration for future revision reconstruction. A previous study analyzed graft choice propensity and determined surgeon choice to have the strongest impact upon graft choice ( $5 \times$ any other factor). ${ }^{6}$ Thus, surgeons can typically utilize the graft they determine to be best for their patient and this underscores the importance of the current study.

Previous studies when not stratified by age or activity have not identified a difference in graft failure rates. Kaeding et al. when utilizing age and activity as part of the analysis demonstrated a fourfold increase in graft failure for allograft in a primary cohort that included some irradiated grafts. ${ }^{12}$ In this current revision cohort autograft predicted improved sports function as measured by IKDC, KOOS subscales Sports and Recreation and QOL. Graft type did not predict MARX activity scales except in the small number of combined allograft/autograft patients. The clinical significance of this finding may be small 
since few patients undergo a revision utilizing this graft combination. A previous analysis of IKDC and KOOS at six years in a primary prospective cohort demonstrated that the use of allograft was a significant predictor of lower IKDC and KOOS Sports and Recreation and QOL subscales. $^{21}$

IKDC scores in the MARS revision cohort demonstrated similar levels seen in previous primary settings. Spindler et al. reported two and six year primary ACL reconstruction median IKDC scores of 75 and 77, respectively, which were similar to our score of 77 at two years. ${ }^{21}$ Wright et al. in a systematic review of ACL revision reconstructions with minimum two year follow-up reported a pooled IKDC in 202 patients of $74.8 .{ }^{26}$ However, unlike the IKDC the KOOS scores in the MARS revision cohort were noted to be clinically significantly lower. Two year median KOOS Sports and recreation was 75 compared to 85 and 90 at two and six years for primary ACL reconstructions reported by Spindler et al. ${ }^{21}$ KOOS QOL was 56 for the MARS cohort versus 75 and 81 (2 and 6 years) in the Spindler et al primary cohort. ${ }^{21}$ The MCID is $8-10$ points for the KOOS. ${ }^{17}$

The Marx activity scores demonstrated dramatic decreases over the two years following revision ACL reconstruction. This occurred in a cohort that is older than the typical primary ACL reconstruction cohort and should have already had a natural decline in activity that we have noted every 2 years in a primary series. ${ }^{21,22}$ The typical activity progression is a decrease from high activity high school sports athlete, to a college intramural/recreational athlete, to full time employment and family obligations. At a median age of 26 year old in this study, most of these patients have already gone through many of these lifestyle changes that would decrease their activity naturally. This drop in activity at two year follow-up more closely resembles previous primary ACL reconstruction cohort activity levels noted at six year follow-up rather than 2 year follow-up. ${ }^{21}$ It is unclear whether the reduction in activity level is because they cannot be active due to the condition of their knee or they have chosen to decrease their activity to decrease the risk of future injury.

The baseline MARX scores acted as a very strong predictor for our 2 year patient reported measures. It predicted 2 year IKDC and four of five KOOS subscales (symptoms excepted) and may be a simple tool to help counsel patients (i.e. if you weren't previously active with your knee in the year prior to revision there is a strong chance you will not be active nor highly satisfied with your knee at two years). Another common predictor was time since last reconstruction. It appears that patients that had several years since their last reconstruction did well following revision. While it cannot be known why this occurs it is possible that patients that coped and functioned for several years previously are more likely to do well again.

Our study has many strengths and a few limitations. This is the largest prospective longitudinal cohort to ever analyze the outcomes of revision ACL reconstructions. The $50 / 50 \mathrm{mix}$ of academic and private practice surgeons makes the results generalizable to the sports medicine fellowship trained community. The use of validated patient reported outcome measures allows us to compare this to future and previous studies that have utilized these measures in other settings. The large number of patients enrolled allows us to perform sophisticated statistical analyses controlling for a large number of variables in order to 
understand the predictors of inferior outcomes noted in revision ACL reconstructions. Our cohort study design resulted in an even split of autograft and allograft patients with high numbers to allow analysis to control for multiple variables without the need for randomization of graft choice, which would have added significant challenges in conducting the study. Our study design is limited in that it currently precludes on-site followup and is limited to two year follow-up. For this reason we may have underestimated the incidence of revision ACL graft rupture. Previous studies have demonstrated higher failure rates at minimum two year follow-up. ${ }^{26}$ This decreased rate may reflect improved results since many of the previous studies were more than ten years old or may reflect a lack of rupture detection in our study design. Future follow-up will address this with on-site clinical assessments.

\section{Conclusions}

Optimal graft choice for revision reconstruction was not known prior to this study. Improved sports function and patient reported outcome measures were obtained when an autograft was utilized. Additionally, use of an autograft showed a decreased risk in graft re-rupture at two years follow-up.

\section{Authors}

Rick W. Wright, MD,

Washington University, St. Louis

Laura J. Huston, MS, Vanderbilt University

Amanda K. Haas, MA, Washington University, St. Louis

Kurt P. Spindler, MD, Vanderbilt University

Sam K. Nwosu, MS, Vanderbilt University

Christina R. Allen, MD, University of California, San Francisco

Allen F. Anderson, MD, Tennessee Orthopaedic Alliance

Daniel E. Cooper, MD, W.B. Carrell Memorial Clinic

Thomas M. DeBerardino, MD, University of Connecticut Health Center

Warren R. Dunn, MD, MPH, University of Wisconsin

Brett (Brick) A. Lantz, MD, 
Slocum Research and Education Foundation

Michael J. Stuart, MD,

Mayo Clinic Rochester

Elizabeth A. Garofoli,

Washington University, St. Louis

John P. Albright, MD,

University of lowa Hospitals and Clinics

Annunziato (Ned) Amendola, MD,

University of lowa Hospitals and Clinics

Jack T. Andrish, MD,

Cleveland Clinic

Christopher C. Annunziata, MD,

Commonwealth Orthopaedics \& Rehab

Robert A. Arciero, MD,

University of Connecticut Health Center

Bernard R. Bach Jr, MD,

Rush University Medical Center

Champ L. Baker III, MD,

The Hughston Clinic

Arthur R. Bartolozzi, MD,

3B Orthopaedics, University of Pennsylvania Health System

Keith M. Baumgarten, MD,

Orthopedic Institute

Jeffery R. Bechler, MD,

University Orthopedic Associates, LLC

Jeffrey H. Berg, MD,

Town Center Orthopaedic Associates

Geoffrey A. Bernas, MD,

State University of New York at Buffalo

Stephen F. Brockmeier, MD,

University of Virginia

Robert H. Brophy, MD,

Washington University, St. Louis

Charles A. Bush-Joseph, MD,

Rush University Medical Center

J. Brad Butler V, MD,

Orthopedic and Fracture Clinic 
John D. Campbell, MD,

Bridger Orthopaedic and Sports Medicine

James L. Carey, MD, MPH,

University of Pennsylvania

James E. Carpenter, MD,

University of Michigan

Brian J. Cole, MD,

Rush University Medical Center

Jonathan M. Cooper, DO,

HealthPartners Specialty Clinic

Charles L. Cox, MD, MPH,

Vanderbilt University

R. Alexander Creighton, MD,

University of North Carolina Medical Center

Diane L. Dahm, MD,

Mayo Clinic Rochester

Tal S. David, MD,

Arthroscopic and Orthopedic Sports Medicine Associates

David C. Flanigan, MD,

The Ohio State University

Robert W. Frederick, MD,

The Rothman Institute/Thomas Jefferson University

Theodore J. Ganley, MD,

Children's Hospital of Philadelphia

Charles J. Gatt Jr, MD,

University Orthopedic Associates, LLC

Steven R. Gecha, MD,

Princeton Orthopaedic Associates

James Robert Giffin, MD,

Fowler Kennedy Sports Medicine Clinic- University of Western Ontario

Sharon L. Hame, MD,

David Geffen School of Medicine at UCLA

Jo A. Hannafin, MD, PhD,

Hospital for Special Surgery

Christopher D. Harner, MD,

University of Pittsburgh Medical Center

Norman Lindsay Harris Jr, MD, 
Orthopaedic Associates of Aspen \& Glenwood

Keith S. Hechtman, MD,

UHZ Sports Medicine Institute

Elliott B. Hershman, MD,

Lenox Hill Hospital

Rudolf G. Hoellrich, MD,

Slocum Research and Education Foundation

Timothy M. Hosea, MD,

University Orthopedic Associates, LLC

David C. Johnson, MD,

National Sports Medicine Institute

Timothy S. Johnson, MD,

National Sports Medicine Institute

Morgan $\mathrm{H}$. Jones, MD,

Cleveland Clinic

Christopher C. Kaeding, MD,

The Ohio State University

Ganesh V. Kamath, MD,

University of North Carolina Medical Center

Thomas E. Klootwyk, MD,

Methodist Sports Medicine Center-The Orthopedic Specialists

Bruce A. Levy, MD,

Mayo Clinic Rochester

C. Benjamin Ma, MD,

University of California, San Francisco

G. Peter Maiers II, MD, Methodist Sports Medicine Center-The Orthopedic Specialists

Robert G. Marx, MD,

Hospital for Special Surgery

Matthew J. Matava, MD,

Washington University, St. Louis

Gregory M. Mathien, MD,

Knoxville Orthopedic Clinic

David R. McAllister, MD,

David Geffen School of Medicine at UCLA

Eric C. McCarty, MD,

University of Colorado Denver School of Medicine 
Robert G. McCormack, MD,

University of British Columbia

Bruce S. Miller, MD, MS,

University of Michigan

Carl W. Nissen, MD,

Connecticut Children's Medical Center

Daniel F. O'Neill, MD, Ed.D,

Littleton Regional Hospital

LTC Brett D. Owens, MD,

Keller Army Community Hospital-United States Military Academy

Richard D. Parker, MD,

Cleveland Clinic

Mark L. Purnell, MD,

Orthopaedic Associates of Aspen \& Glenwood

Arun J. Ramappa, MD,

Beth Israel Deaconess Medical Center

Michael A. Rauh, MD,

State University of New York at Buffalo

Arthur C. Rettig, MD,

Methodist Sports Medicine Center-The Orthopedic Specialists

Jon K. Sekiya, MD,

University of Michigan

Kevin G. Shea, MD, Intermountain Orthopedics

Orrin H. Sherman, MD,

NYU Hospital for Joint Diseases

James R. Slauterbeck, MD,

University of Vermont College of Medicine

Matthew V. Smith, MD,

Washington University, St. Louis

Jeffrey T. Spang, MD,

University of North Carolina Medical Center

LTC. Steven J. Svoboda, MD,

Keller Army Community Hospital-United States Military Academy

Timothy N. Taft, MD,

University of North Carolina Medical Center

COL Joachim J. Tenuta, MD, 
Keller Army Community Hospital-United States Military Academy

Edwin M. Tingstad, MD,

Inland Orthopaedics/ Washington State University

Armando F. Vidal, MD,

University of Colorado Denver School of Medicine

Darius G. Viskontas, MD,

Royal Columbian Hospital

Richard A. White, MD,

University of Missouri-Columbia

James S. Williams Jr, MD,

Cleveland Clinic

Michelle L. Wolcott, MD,

University of Colorado Denver School of Medicine

Brian R. Wolf, MD, and

University of lowa Hospitals and Clinics

James J. York, MD

Chesapeake Orthopaedics \& Sports Medicine Center

\section{Affiliations}

Washington University, St. Louis

Vanderbilt University

Washington University, St. Louis

Vanderbilt University

Vanderbilt University

University of California, San Francisco

Tennessee Orthopaedic Alliance

W.B. Carrell Memorial Clinic

University of Connecticut Health Center

University of Wisconsin

Slocum Research and Education Foundation

Mayo Clinic Rochester

Washington University, St. Louis

University of lowa Hospitals and Clinics

University of lowa Hospitals and Clinics

Cleveland Clinic 
Commonwealth Orthopaedics \& Rehab

University of Connecticut Health Center

Rush University Medical Center

The Hughston Clinic

3B Orthopaedics, University of Pennsylvania Health System

Orthopedic Institute

University Orthopedic Associates, LLC

Town Center Orthopaedic Associates

State University of New York at Buffalo

University of Virginia

Washington University, St. Louis

Rush University Medical Center

Orthopedic and Fracture Clinic

Bridger Orthopaedic and Sports Medicine

University of Pennsylvania

University of Michigan

Rush University Medical Center

HealthPartners Specialty Clinic

Vanderbilt University

University of North Carolina Medical Center

Mayo Clinic Rochester

Arthroscopic and Orthopedic Sports Medicine Associates

The Ohio State University

The Rothman Institute/Thomas Jefferson University

Children's Hospital of Philadelphia

University Orthopedic Associates, LLC

Princeton Orthopaedic Associates

Fowler Kennedy Sports Medicine Clinic- University of Western Ontario

David Geffen School of Medicine at UCLA

Hospital for Special Surgery

University of Pittsburgh Medical Center

Orthopaedic Associates of Aspen \& Glenwood 
UHZ Sports Medicine Institute

Lenox Hill Hospital

Slocum Research and Education Foundation

University Orthopedic Associates, LLC

National Sports Medicine Institute

National Sports Medicine Institute

Cleveland Clinic

The Ohio State University

University of North Carolina Medical Center

Methodist Sports Medicine Center-The Orthopedic Specialists

Mayo Clinic Rochester

University of California, San Francisco

Methodist Sports Medicine Center-The Orthopedic Specialists

Hospital for Special Surgery

Washington University, St. Louis

Knoxville Orthopedic Clinic

David Geffen School of Medicine at UCLA

University of Colorado Denver School of Medicine

University of British Columbia

University of Michigan

Connecticut Children's Medical Center

Littleton Regional Hospital

Keller Army Community Hospital-United States Military Academy

Cleveland Clinic

Orthopaedic Associates of Aspen \& Glenwood

Beth Israel Deaconess Medical Center

State University of New York at Buffalo

Methodist Sports Medicine Center-The Orthopedic Specialists

University of Michigan

Intermountain Orthopedics

NYU Hospital for Joint Diseases

University of Vermont College of Medicine 
Washington University, St. Louis

University of North Carolina Medical Center

Keller Army Community Hospital-United States Military Academy

University of North Carolina Medical Center

Keller Army Community Hospital-United States Military Academy

Inland Orthopaedics/ Washington State University

University of Colorado Denver School of Medicine

Royal Columbian Hospital

University of Missouri-Columbia

Cleveland Clinic

University of Colorado Denver School of Medicine

University of lowa Hospitals and Clinics

Chesapeake Orthopaedics \& Sports Medicine Center

\section{Acknowledgments}

This study received funding from the AOSSM, Smith and Nephew (Andover, MA), National Football League Charities (New York, NY), and Musculoskeletal Tissue Foundation (MTF, Edison, NJ). This project was partially funded by grant no. 5R01-AR060846 from the National Institutes of Health/National Institute of Arthritis and Musculoskeletal and Skin Diseases (NIH/NIAMS).

\section{Bibliography}

1. Bellamy N. Pain assessment in osteoarthritis: experience with the WOMAC osteoarthritis index. Semin Arthritis Rheum. 1989; 18(4 Suppl 2):14-17. [PubMed: 2786253]

2. Bellamy N. WOMAC: a 20-year experiential review of a patient-centered self-reported health status questionnaire. J Rheumatol. 2002; 29(12):2473-2476. [PubMed: 12465137]

3. Carey JL, Dunn WR, Dahm DL, Zeger SL, Spindler KP. A systematic review of anterior cruciate ligament reconstruction with autograft compared with allograft. J Bone Joint Surg Am. 2009; 91(9): 2242-2250. [PubMed: 19724004]

4. Foster TE, Wolfe BL, Ryan S, Silvestri L, Kaye EK. Does the graft source really matter in the outcome of patients undergoing anterior cruciate ligament reconstruction? An evaluation of autograft versus allograft reconstruction results: a systematic review. Am J Sports Med. 2010; 38(1):189-199. [PubMed: 20051509]

5. George MS, Dunn WR, Spindler KP. Current concepts review: revision anterior cruciate ligament reconstruction. Am J Sports Med. 2006; 34(12):2026-2037. [PubMed: 17092921]

6. Group M. Factors Influencing Graft Choice in Revision ACL Reconstructions: A Propensity Analysis of the MARS Cohort. JBJS. 2013 Submitted.

7. Group M, Wright RW, Huston LJ, Spindler KP, Dunn WR, Haas AK, Allen CR, Cooper DE, DeBerardino TM, Lantz BB, Mann BJ, Stuart MJ. Descriptive epidemiology of the Multicenter ACL Revision Study (MARS) cohort. Am J Sports Med. 2010; 38(10):1979-1986. [PubMed: 20889962]

8. Hawker G, Melfi C, Paul J, Green R, Bombardier C. Comparison of a generic (SF-36) and a disease specific (WOMAC) (Western Ontario and McMaster Universities Osteoarthritis Index) instrument in the measurement of outcomes after knee replacement surgery. J Rheumatol. 1995; 22(6):11931196. [PubMed: 7674255] 
9. Ihaka R, Gentleman R. R: A language for data analysis and graphics. Journal of Computational and Graphical Statistics. 1996; 5(3):299-314.

10. Irrgang JJ, Anderson AF, Boland AL, Harner CD, Kurosaka M, Neyret P, Richmond JC, Shelborne KD. Development and validation of the international knee documentation committee subjective knee form. Am J Sports Med. 2001; 29(5):600-613. [PubMed: 11573919]

11. Irrgang JJ, Anderson AF, Boland AL, Harner CD, Neyret P, Richmond JC, Shelbourne KD. Responsiveness of the International Knee Documentation Committee Subjective Knee Form. Am J Sports Med. 2006; 34(10):1567-1573. [PubMed: 16870824]

12. Kaeding CC, Aros B, Pedroza A, Pifel E, Amendola A, Andrish JT, Dunn WR, Marx RG, McCarty EC, Parker RD, Wright RW, Spindler KP. Allograft Versus Autograft Anterior Cruciate Ligament Reconstruction: Predictors of Failure From a MOON Prospective Longitudinal Cohort. Sports Health. 2011; 3(1):73-81. [PubMed: 23015994]

13. Kamath GV, Redfern JC, Greis PE, Burks RT. Revision anterior cruciate ligament reconstruction. Am J Sports Med. 2011; 39(1):199-217. [PubMed: 20709943]

14. Krych AJ, Jackson JD, Hoskin TL, Dahm DL. A meta-analysis of patellar tendon autograft versus patellar tendon allograft in anterior cruciate ligament reconstruction. Arthroscopy. 2008; 24(3): 292-298. [PubMed: 18308180]

15. Marx RG, Stump TJ, Jones EC, Wickiewicz TL, Warren RF. Development and evaluation of an activity rating scale for disorders of the knee. Am J Sports Med. 2001; 29(2):213-218. [PubMed: 11292048]

16. Outerbridge RE. The etiology of chondromalacia patellae. J Bone Joint Surg Br. 1961; 43-B:752757. [PubMed: 14038135]

17. Roos EM, Lohmander LS. The Knee injury and Osteoarthritis Outcome Score (KOOS): from joint injury to osteoarthritis. Health Qual Life Outcomes. 2003; 1(1):64. [PubMed: 14613558]

18. Roos EM, Roos HP, Ekdahl C, Lohmander LS. Knee injury and Osteoarthritis Outcome Score (KOOS)--validation of a Swedish version. Scand J Med Sci Sports. 1998; 8(6):439-448. [PubMed: 9863983]

19. Roos EM, Roos HP, Lohmander LS, Ekdahl C, Beynnon BD. Knee Injury and Osteoarthritis Outcome Score (KOOS)--development of a self-administered outcome measure. J Orthop Sports Phys Ther. 1998; 28(2):88-96. [PubMed: 9699158]

20. Roos EM, Toksvig-Larsen S. Knee injury and Osteoarthritis Outcome Score (KOOS) - validation and comparison to the WOMAC in total knee replacement. Health Qual Life Outcomes. 2003; 1(1):17. [PubMed: 12801417]

21. Spindler KP, Huston LJ, Wright RW, Kaeding CC, Marx RG, Amendola A, Parker RD, Andrish JT, Reinke EK, Harrell FE Jr, Group M, Dunn WR. The prognosis and predictors of sports function and activity at minimum 6 years after anterior cruciate ligament reconstruction: a population cohort study. Am J Sports Med. 2011; 39(2):348-359. [PubMed: 21084660]

22. Spindler KP, Parker RD, Andrish JT, Kaeding CC, Wright RW, Marx RG, McCarty EC, Amendola A, Dunn WR, Huston LJ, Harrell FE Jr, Group M. Prognosis and predictors of ACL reconstructions using the MOON cohort: a model for comparative effectiveness studies. J Orthop Res. 2013; 31(1):2-9. [PubMed: 22912340]

23. Wright RW. Knee injury outcomes measures. J Am Acad Orthop Surg. 2009; 17(1):31-39. [PubMed: 19136425]

24. Wright RW. Knee sports injury outcome measures. J Knee Surg. 2005; 18(1):69-72. [PubMed: 15742600]

25. Wright RW, Dunn WR, Amendola A, Andrish JT, Flanigan DC, Jones M, Kaeding CC, Marx RG, Matava MJ, McCarty EC, Parker RD, Vidal A, Wolcott M, Wolf BR, Spindler KP, Cohort M. Anterior cruciate ligament revision reconstruction: two-year results from the MOON cohort. J Knee Surg. 2007; 20(4):308-311. [PubMed: 17993075]

26. Wright RW, Gill CS, Chen L, Brophy RH, Matava MJ, Smith MV, Mall NA. Outcome of revision anterior cruciate ligament reconstruction: a systematic review. J Bone Joint Surg Am. 2012; 94(6): 531-536. [PubMed: 22438002] 


\section{What is known about this subject}

Previous studies have demonstrated that revision ACL reconstruction outcomes are worse than primary ACL reconstructions. Most previous research has been Level 4 studies and the reason for worse outcomes has not been well elucidated. 


\section{What this study adds to existing knowledge}

This prospective multi-center cohort at two year follow-up demonstrates that the use of autograft for revision reconstruction results in improved patient reported outcomes as determined by KOOS subscales Sports and Recreation and Quality of Life and the IKDC. The use of an autograft for revision reconstruction resulted in patients 2.78 times less likely to sustain a graft rerupture within 2 years. 


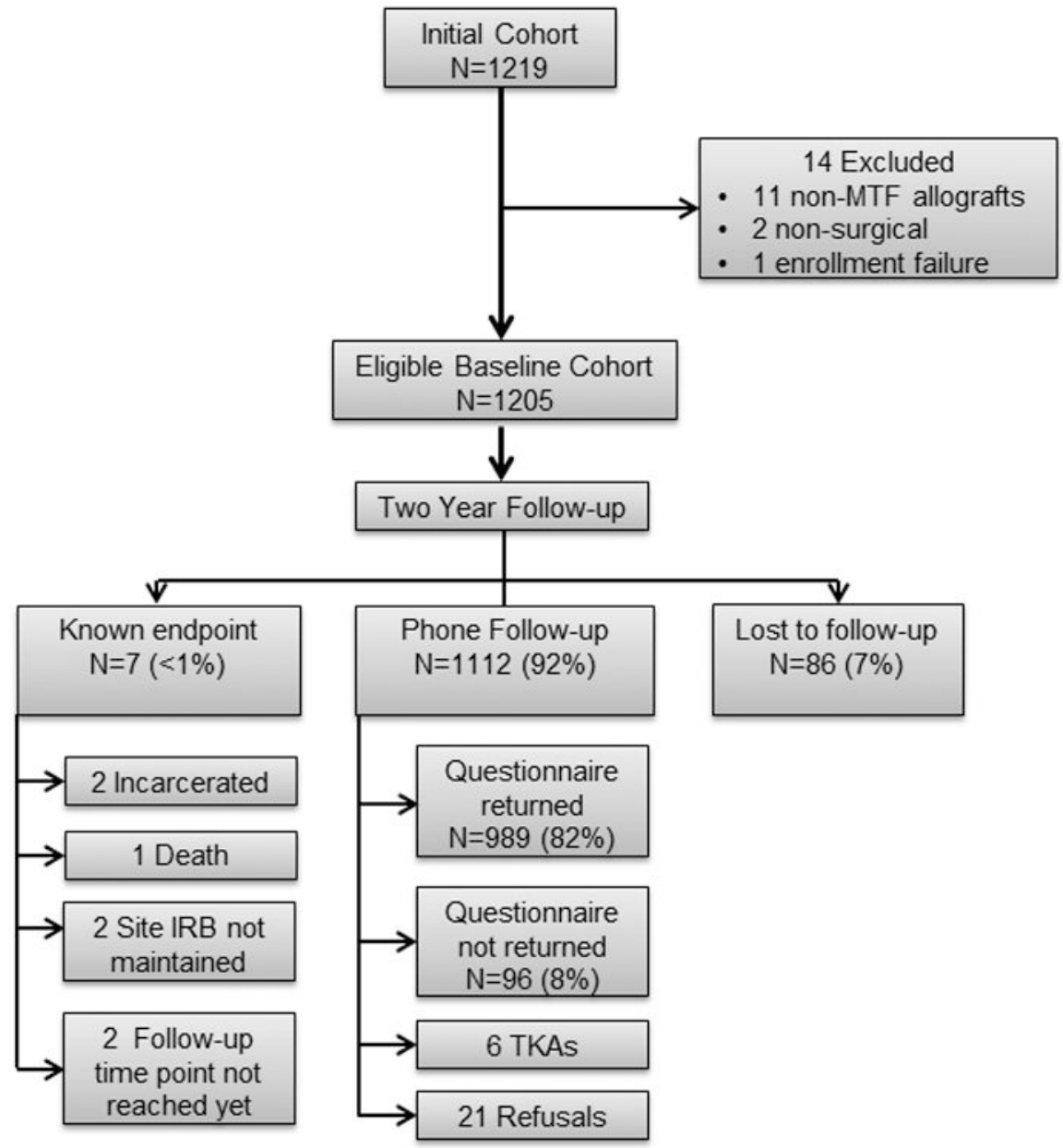

Figure 1. Patient Enrollment Flow Diagram 
Table 1

List of Independent Modelling Variables

\begin{tabular}{|c|c|c|c|}
\hline Category & Variable & $\begin{array}{l}\text { Degrees of } \\
\text { Freedom } \\
\text { (df) }\end{array}$ & Levels \\
\hline Baseline Outcome Score & $\begin{array}{l}\text { IKDC, KOOS ( } 5 \text { subscales), WOMAC ( } 3 \\
\text { subscales), or Marx }\end{array}$ & 1 & continuous \\
\hline Patient Demographics & $\begin{array}{l}\text { Age (years) } \\
\text { Gender } \\
\text { BMI } \\
\text { Smoking status } \\
\text { Education level (years) } \\
\text { Baseline activity level (Marx) }\end{array}$ & $\begin{array}{l}1 \\
1 \\
1 \\
2 \\
1 \\
1\end{array}$ & $\begin{array}{l}\text { continuous } \\
\text { male, female } \\
\text { continuous } \\
\text { never, quit, current } \\
\text { continuous (range from } 1 \text { - 16) } \\
\text { continuous }\end{array}$ \\
\hline Previous Surgical Information & $\begin{array}{l}\text { Revision number } \\
\text { Time since last ACLR (yrs) } \\
\text { Previous ACLR on contralateral knee } \\
\text { Previous meniscal surgery type } \\
* \text { medial } \\
\text { * lateral } \\
\text { \# of previous articular cartilage surgeries } \\
\text { Surgeon's opinion of failure } \\
\text { Surgeon's revision his/her own failure } \\
\text { Cause of technical failure } \\
\text { Prior graft type } \\
\text { Prior graft source }\end{array}$ & $\begin{array}{l}3 \\
3 \\
1 \\
1 \\
4 \\
1 \\
4 \\
3 \\
3\end{array}$ & $\begin{array}{l}1,2,3 \text { or more } \\
\text { continuous } \\
\text { no, yes } \\
\text { no, yes - repair healed/stable, yes - } \\
\text { repair not healed/unstable, yes - } \\
\text { excision } \\
\text { no, yes - repair healed/stable, yes - } \\
\text { repair not healed/unstable, yes - } \\
\text { excision } \\
\text { no, yes } \\
\text { traumatic, technical, biologic, other, } \\
\text { combination } \\
\text { no, yes } \\
\text { femoral tunnel malposition, tibial } \\
\text { tunnel malposition, femoral+tibial } \\
\text { malposition, other, none } \\
\text { autograft, allograft, both autograft + } \\
\text { allograft, unknown } \\
\text { BTB, soft tissue, BTB+soft tissue, } \\
\text { other/unknown }\end{array}$ \\
\hline $\begin{array}{c}\text { Current Surgical Technique and } \\
\text { Findings }\end{array}$ & $\begin{array}{l}\text { Mechanism of injury } \\
\text { CURRENT GRAFT TYPE } \\
\text { CURRENT GRAFT SOURCE } \\
\text { Interaction of (current graft type) } \\
\text { (current graft source) } \\
\text { Current Surgical Exposure/Technique } \\
\text { Current Femoral Tunnel Aperture Position }\end{array}$ & $\begin{array}{l}3 \\
2 \\
2 \\
4\end{array}$ & $\begin{array}{l}\text { non-traumatic gradual onset, non- } \\
\text { traumatic sudden onset, traumatic } \\
\text { non-contact, traumatic contact } \\
\text { autograft, allograft, both } \\
\text { BTB, soft tissue, other } \\
2 \times 2 \\
1 \text { incision (trans-tibial), } 1 \text { incision } \\
(\text { AM portal), } 2 \text { incision, arthrotomy/ } \\
\text { other } \\
\text { optimum position, same tunnel - but } \\
\text { compromised position, blended new } \\
\text { tunnel, entirely new tunnel, added a } \\
\text { 2nd tunnel, OTT }\end{array}$ \\
\hline
\end{tabular}




\begin{tabular}{|c|c|c|c|c|}
\hline 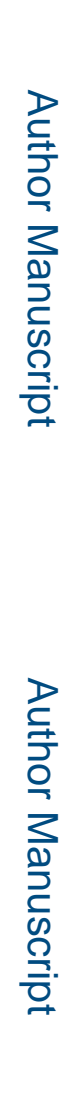 & Category & $\begin{array}{l}\text { Variable } \\
\text { Current Tibial Tunnel Aperture Position } \\
\text { Current Femoral Fixation } \\
\text { Current Tibial Fixation } \\
\text { Biologic Enhancement } \\
\text { Meniscal pathology } \\
\text { * medial } \\
\text { * lateral } \\
\text { Articular cartilage pathology } \\
\text { * medial femoral condyle (MFC) } \\
\text { * lateral femoral condyle (LFC) } \\
\text { * medial tibial plateau (MTP) } \\
* \text { lateral tibial plateau (LTP) } \\
* \text { patella } \\
* \text { trochlea } \\
\text { Surgeon years of experience }\end{array}$ & $\begin{array}{c}\begin{array}{c}\text { Degrees of } \\
\text { Freedom } \\
\text { (df) }\end{array} \\
4 \\
4 \\
4 \\
1\end{array}$ & $\begin{array}{l}\text { Levels } \\
\text { optimum position, same tunnel - but } \\
\text { compromised position, blended new } \\
\text { tunnel, entirely new tunnel, added a } \\
\text { 2nd tunnel } \\
\text { interference screw, suture+button/ } \\
\text { endo, cross pin, other, combination } \\
\text { interference screw, intrafix, suture } \\
\text { +button/endo or post, other, } \\
\text { combination } \\
\text { no, yes } \\
\text { normal, no treatment for tear, repair, } \\
\text { excision, other } \\
\text { normal, no treatment for tear, repair, } \\
\text { excision, other } \\
\text { normal/grade 1, grade 2, grade 3, } \\
\text { grade } 4 \\
\text { normal/grade 1, grade 2, grade 3, } \\
\text { grade } 4 \\
\text { normal/grade 1, grade 2, grades } 3 / 4 \\
\text { normal/grade 1, grade 2, grades } 3 / 4 \\
\text { normal/grade } 1 \text {, grade } 2 \text {, grades } 3 / 4 \\
\text { normal/grade 1, grade } 2 \text {, grades } 3 / 4 \\
\text { continuous }\end{array}$ \\
\hline
\end{tabular}

Total \# of Degrees of Freedom: 88 
Table 2

Baseline Patient and Surgical Characteristics $(n=1205)$

\begin{tabular}{|c|c|}
\hline & $\mathbf{N}(\%)$ \\
\hline \multicolumn{2}{|l|}{ Patient Demographics } \\
\hline \multicolumn{2}{|l|}{ Gender } \\
\hline - Males & $697(58 \%)$ \\
\hline \multirow[t]{2}{*}{ - Females } & $508(42 \%)$ \\
\hline & 20 \\
\hline \multirow[t]{3}{*}{ Age (years) } & 26 \\
\hline & 34 \\
\hline & 22.6 \\
\hline \multirow[t]{3}{*}{ BMI } & 25.1 \\
\hline & 28.5 \\
\hline & 12 \\
\hline \multirow[t]{3}{*}{ Education (years) } & 15 \\
\hline & 16 \\
\hline & 4 \\
\hline \multirow[t]{2}{*}{ Baseline activity level (Marx) } & 11 \\
\hline & 16 \\
\hline \multicolumn{2}{|l|}{ Smoking Status } \\
\hline • Never & $923(77 \%)$ \\
\hline • Quit & $154(13 \%)$ \\
\hline - Current & $109(9 \%)$ \\
\hline \multicolumn{2}{|l|}{ Previous Surgical Information } \\
\hline & 1.4 \\
\hline \multirow[t]{2}{*}{ Time since last ACLR (years) } & 3.4 \\
\hline & 8.3 \\
\hline \multicolumn{2}{|l|}{ Revision number } \\
\hline$\cdot 1$ & $1055(88 \%)$ \\
\hline$\cdot 2$ & $125(10 \%)$ \\
\hline - 3 or more & $25(2 \%)$ \\
\hline \multicolumn{2}{|l|}{ Previous ACLR on contralateral knee } \\
\hline$\bullet$ No & $1083(90 \%)$ \\
\hline - Yes & $122(10 \%)$ \\
\hline \multicolumn{2}{|l|}{ Previous Medial Meniscus Surgery } \\
\hline$\bullet$ No & $743(62 \%)$ \\
\hline - Yes, repair healed/stable & $31(3 \%)$ \\
\hline - Yes, repair not healed/unstable & $68(6 \%)$ \\
\hline - Yes, excision & $362(30 \%)$ \\
\hline \multicolumn{2}{|l|}{ Previous Lateral Meniscus Surgery } \\
\hline$\cdot$ No & $958(80 \%)$ \\
\hline
\end{tabular}




\begin{tabular}{|c|c|}
\hline & $\mathbf{N}(\%)$ \\
\hline - Yes, repair healed/stable & $28(2 \%)$ \\
\hline - Yes, repair not healed/unstable & $23(2 \%)$ \\
\hline - Yes, excision & $195(16 \%)$ \\
\hline \multicolumn{2}{|l|}{ Previous articular cartilage surgeries } \\
\hline • No & $1059(88 \%)$ \\
\hline • Yes & $146(12 \%)$ \\
\hline \multicolumn{2}{|l|}{ Surgeon's opinion of failure } \\
\hline - Traumatic & $405(34 \%)$ \\
\hline - Technical & $265(22 \%)$ \\
\hline - Biologic & $108(9 \%)$ \\
\hline - Other & $27(2 \%)$ \\
\hline - Combination & $398(33 \%)$ \\
\hline
\end{tabular}

Surgeon's revision his/her own failure

- No

$859(71 \%)$

- Yes

$341(28 \%)$

Prior Graft Type

- Autograft

$816(68 \%)$

- Allograft

$348(29 \%)$

- Both autograft + allograft

$29(2 \%)$

- Other/unknown

$12(<1 \%)$

Prior Graft Source

- BTB

$639(53 \%)$

- Soft Tissue

$459(38 \%)$

- BTB + Soft Tissue

$14(1 \%)$

- Other/unknown

$93(8 \%)$

Current Surgical Information

\begin{tabular}{rc}
\hline & 8 \\
Surgeon years of experience & 13 \\
& 18 \\
Mechanism of Injury & \\
• Non-traumatic; gradual & $339(28 \%)$ \\
• Non-traumatic; sudden onset & $84(7 \%)$ \\
• Traumatic; non-contact & $636(53 \%)$ \\
- Traumatic; contact & $144(12 \%)$ \\
Current Graft Type & \\
- Autograft & \\
318 & BTB \\
18 & quad-bone \\
224 & Hamstring (SG+G) \\
20 & Hamstring (ST) \\
1 & two soft tissue combinations
\end{tabular}




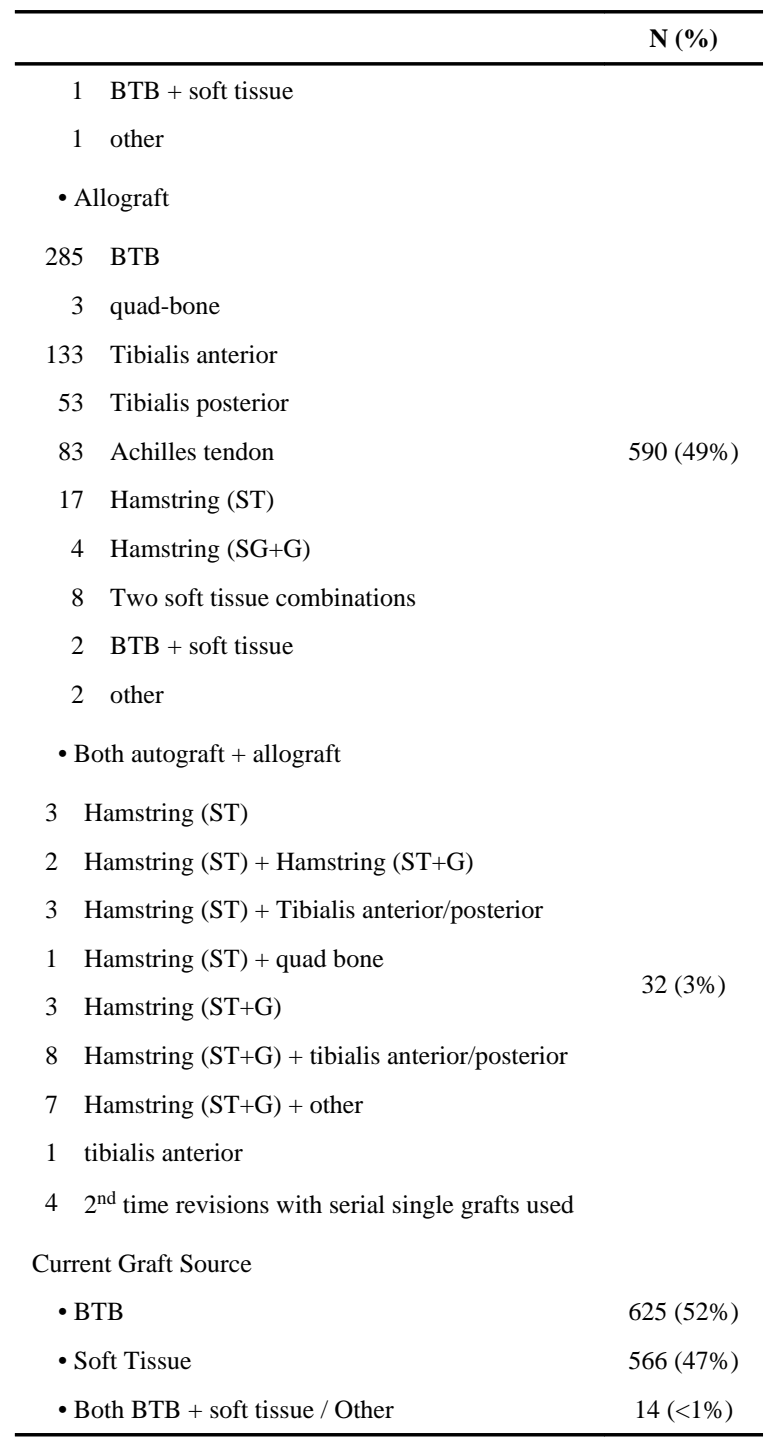

Note: $\mathrm{a} b \mathrm{c}$ represents the lower quartile $\mathrm{a}$, the median $\mathrm{b}$, and the upper quartile $\mathrm{c}$ for continuous variables. 
Table 3

Median (25\%, $75 \%$ quartile) Outcome Scores over Time

\begin{tabular}{|l|c|c|c|}
\hline & Scale & Baseline - T & 2 Year \\
\hline IKDC & $0-100$ & $52(38,63)$ & $77(61,86)^{*}$ \\
\hline KOOS & & & \\
\hline$\cdot$ Symptoms & $0-100$ & $68(54,82)$ & $79(64,89)^{*}$ \\
\hline$\cdot$ Pain & $0-100$ & $75(58,86)$ & $89(75,94)^{*}$ \\
\hline$\cdot$ ADL & $0-100$ & $87(69,96)$ & $97(88,100)^{*}$ \\
\hline$\bullet$ Sports/recreation & $0-100$ & $45(25,65)$ & $75(55,90)^{*}$ \\
\hline$\bullet$ Quality of Life (QOL) & $0-100$ & $31(19,44)$ & $56(38,75)^{*}$ \\
\hline WOMAC & & & \\
\hline$\cdot$ Stiffness & $0-100$ & $75(50,88)$ & $75(62,100)$ \\
\hline • Pain & $0-100$ & $85(70,95)$ & $95(80,100)^{*}$ \\
\hline$\cdot$ ADL & $0-100$ & $87(69,96)$ & $97(88,100)^{*}$ \\
\hline Marx Activity Level & $0-16$ & $11(4,16)$ & $7(2,12)^{*}$ \\
\hline
\end{tabular}

denotes a significant difference in outcome score, compared to baseline score $(\mathrm{p}<0.001)$ 